\title{
Satellite monitoring of geo-hazards affecting cultural heritage
}

Daniele Spizzichino and Claudio Margottini

\section{Rationale and theoretical background}

A comprehensive investigation for all UNESCO sites in the world, with a simplified methodology, was proposed by Pavlova et al. (2017). Onsite observation has been the most common way of studying and monitoring the world's cultural heritage sites and monuments. However, this procedure, which includes field surveying, ground-based data collection and periodical observations, is time-consuming and expensive. Moreover, the installation of monitoring devices, such as optical targets, GPS stations or inclinometers, on the heritage sites and monuments can lead to aesthetic and functional impacts that can affect the integrity and availability of the heritage. Since 1992, new space technology based on radar interferometry has been capable of monitoring, with millimetre precision, surface deformation for reflective targets named persistent scatters (PS), which consistently return stable signals to the radar satellites. A special project (PROTHEGO) applying this new technique was recently approved by the European countries funding heritage research, together with the European Commission (Joint Programming Initiative on Cultural Heritage and Global Change (JPI-CH)), in order to provide a standard methodology for all monuments and sites that are potentially unstable due to landslides, sinkholes, settlement, subsidence, active tectonics and structural deformation, all of which could be amplified by climate change and human interaction. After the remote sensing investigation, detailed geological interpretation, hazard analysis, local-scale monitoring, advanced modelling and field surveying for the most critical sites were carried out to discover the cause and extent of the observed motions. To magnify the impact of the project, the 
approach was implemented in all 399 sites on the UNESCO World Heritage List (WHL) in continental Europe.

Based on the literature, a number of guiding principles are suggested for the improvement of management plans and the integration of hazard and risk in cultural heritage (e.g. Taboroff 2000; UNESCO et al. 2010; Michalski and Pedersoli, Jr. 2017). These studies aim also to reduce the risks to World Heritage properties from natural and human-made disasters, and provide methodology to identify, assess and mitigate disaster risks. Despite this, since the many threats show different areal impacts (e.g. earthquake vs. landslide) involving local or regional environmental processes, a homogeneous overview of expected risk for cultural heritage is still missing and probably also beyond the state of the art. In fact, since a cultural heritage site is a local exposed element, any 'rigorous' risk assessment methodology must be developed at local level and, later on, harmonized at regional/global scale (Margottini and Menoni 2018). On the other side, the lack of a regional/global rank in the expected risk is complicating the prioritization of intervention and allocation of funds for those international agencies and/or governmental organizations dealing with heritage conservation.

\section{Project main objectives}

The PROTHEGO project aims at developing, in the UNESCO World Heritage Sites of Europe, a local-global-local approach, by means of:

1. high-resolution local monitoring based on satellite radar interferometry;

2. definition of a qualitative global hazard analysis and risk assessment for three available threats: earthquake, landslide and volcano; comparison of local satellite monitoring with global risk assessment;

3. selecting high-risk heritage sites and calibration of satellite data with traditional geotechnical monitoring and local site engineering surveys.

The satellite radar interferometry (InSAR) was therefore the connection between local ground deformation monitoring (mirroring surfaces of the order of a few $\mathrm{m}^{2}$ for new satellite constellations - e.g. Cosmo SkyMed - with accuracy of $\mathrm{mm}$ ), a preliminary standard hazard analysis and risk assessment at regional/global level and a final investigation at local level for potentially risk-prone heritage sites. SAR (Synthetic Aperture Radar) is a form of radar that is used to obtain images of objects, such as landscapes or other static targets. Interferometry is a family of techniques in which, usually, electromagnetic 
waves acquired at different times are superimposed in order to extract information about the waves (phases and amplitude). When using radar waves, the technique is called SAR Interferometry or InSAR. The original values, which range from $-p$ to $+p$ (as they correspond to phase variations), are converted to a map of elevation changes with mm accuracy (PS: Permanent Scatterer or Persistent Scatterer technique). To test the methodology and to demonstrate the potentiality offered by this new technique, all the 399 cultural heritage sites in continental Europe inscribed in the UNESCO WHL have been analysed. The first step was to provide an updated and actual geographical overview and a detailed analysis of available datasets concerning WHL sites and geo-hazards in Europe. For the first time, the contour data of the 399 UNESCO sites located in continental Europe have been collected and/or and digitized, in terms of core and buffer zones, in a common format with a standard procedure, and into a unique GIS platform (Spizzichino et al. 2016). Data came from national authorities, UNESCO Focal Points and Open Data Catalogues (39 per cent) and by new digitizing of UNESCO jpeg/pdf documentation (61 per cent), allowing the realization of 2351 core polygons and 932 buffer polygons belonging to the 399 sites. In a second step, a catalogue of satellite-derived ground motion information was collected from the sites, based on interferometric Synthetic Aperture Radar (InSAR) data, elaborated with PS techniques. For all the 399 sites, the available satellite data has been made accessible through a dedicated web site (www.protego.eu). The research activity was implemented through the analysis of satellite InSAR and PS datasets available at European scale. The harmonization of InSAR and PS ground motion data was carried out through the creation of digital factsheets. The final goal of the project was to generate a GIS catalogue of the available satellite InSAR data for the UNESCO WHL sites of Europe (Prothego mapviewer), and digital factsheets summarizing the observed ground motion velocities and deformation histories of the PS reflectors within each WHL site (Cigna and Tapete 2017).

The polygons were compared with natural hazards available at European Union (EU) level, such as earthquakes, landslides and volcanic eruptions. Of the European Heritage Sites (EHS), 16 per cent belong to the High seismic hazards category, 12 per cent are located in Very High landslide susceptibility zones and 14 per cent in High susceptibility zones, and 26 EHS are in High volcanic hazard areas (Figure 11.1). In this project, flood and subsidence hazards were not considered, even if suitable to be investigated by InSAR, due to the lack of a homogeneous EU map. A GIS-based multi-criteria risk analysis was implemented to identify and rank the most critical UNESCO WHL sites at the European scale. The method was based on a quantitative heuristic analysis, which was preferred over probabilistic or deterministic approaches due to the lack of homogeneous information on the probability of occurrence of hazard 
and the impossibility of assessing the vulnerability or fragility of the many European heritage sites in a homogeneous way (Valagussa et al. 2018).

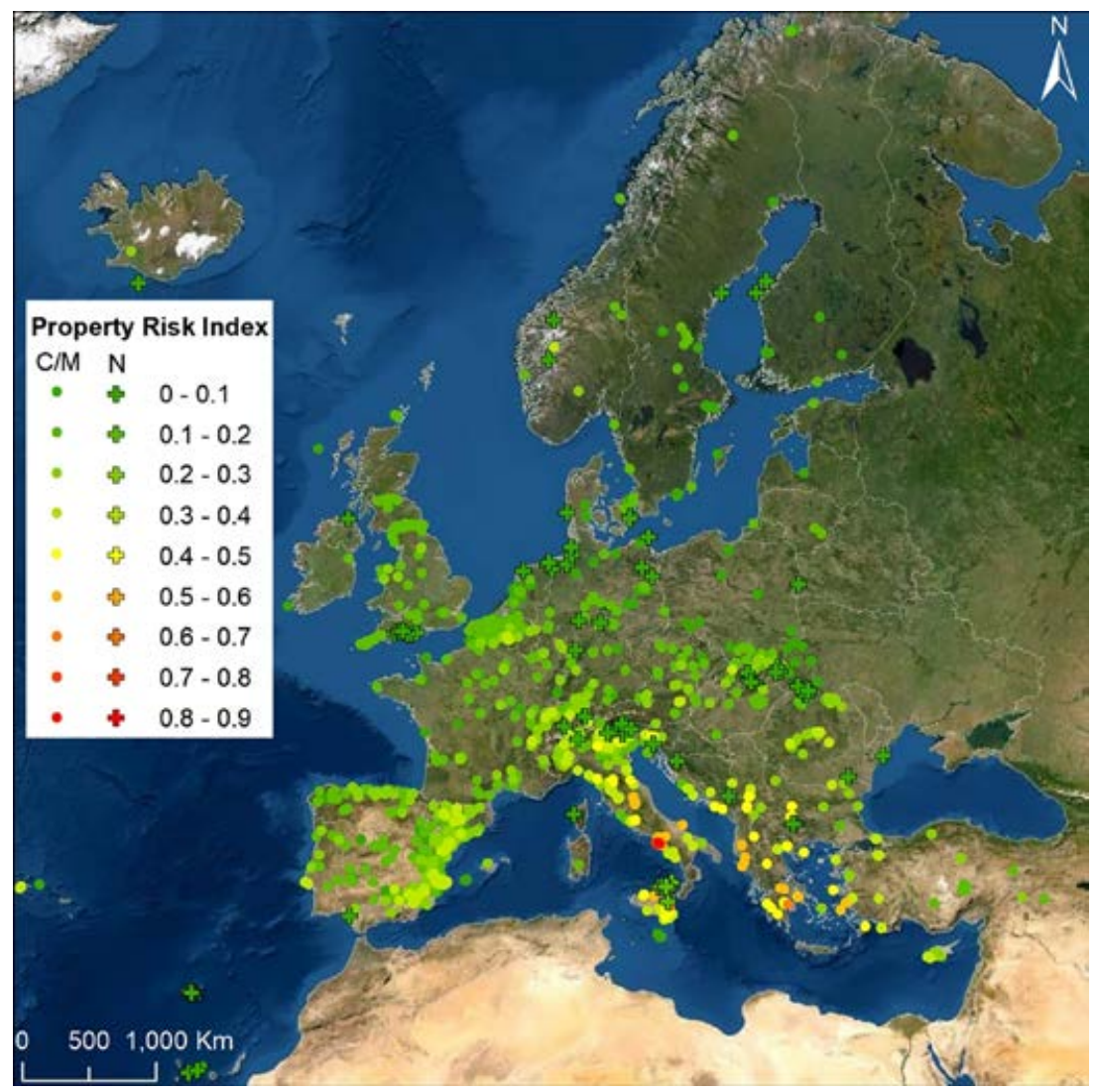

Note: The sites were divided into cultural and mixed sites (C/M - dot) and natural sites ( $\mathrm{N}$ - cross). The values were linearly rescaled between 0 and 1 on the basis of the highest possible risk.

Source: Modified from Valagussa et al. (2018), https://creativecommons.org/ licenses/by/4.0/.

Figure 11.1 Risk ranking of the 2,351 WHS property parts based on the multi-criteria methodology

Finally, in selected case studies, the Satellite Interferometry analysis was validated, calibrated and tested through site-scale field surveys, geotechnical advanced models and detailed monitoring data, by means of traditional geotechnical monitoring and advanced diagnosis. Local-scale monitoring can 
then be used for damage assessment, identification, monitoring and conservation procedures. All the data were placed in a proper web GIS and summarized in a factsheet for any UNESCO heritage site, at www.prothego.eu.

\section{Lessons learned from applying the technique to the case studies}

The Satellite Interferometry analysis was validated, calibrated and tested through site-scale field surveys, geotechnical advanced models and detailed monitoring data, following the above-mentioned methodological framework (diagnosis, monitoring, mitigation and preservation). Seven more in-detail case studies (Themistocleous et al. 2016a; Themistocleou 2016b; Mateos et al. 2018) were chosen (at least one for each partner country). The test sites are described below.

\section{The Aurelian Wall in Rome (Italy)}

The ancient city walls were investigated using high-resolution satellite radar images (CSKmed ${ }^{\circ}$ ASI mission data from 2011 to 2014) and PS InSAR techniques (Figure 11.2). The entire circuit (both Mura Aureliane and Mura Gianicolensi) was digitalized and geo-referenced. Possible deformations, cracks and ruptures due to the interaction between hazards (e.g. subsidence, landslides, earthquakes, excavations, sinkholes) and archaeological remains were investigated, highlighted and identified at site-specific scale. A specific data sheet of several ruptures was created and filled in to produce a geographic inventory of past damage as a tool for future conservation polices. This case study was implemented in cooperation with Sovrintendenza Capitolina ai Beni Culturali of Rome (Leoni et al. 2020).

\section{The Derwent Valley Mills (UK)}

The Derwent Valley Mills (DVM) World Heritage Site is the birthplace of the modern factory system. The Derwent Valley and its associated mill complexes, infrastructure and housing facilities were included in the UNESCO WHL in 2001. The current state of activity of the identified geo-hazards was monitored using Sentinel-1 space-borne imageries (Copernicus program) acquired between 2015 and 2017 and processed using the InSAR technique. The technique allowed the researchers to clearly identify damages connected to a recent flooding event in Belper town. This case study was implemented in 
138 A RESEARCH AGENDA FOR HERITAGE PLANNING

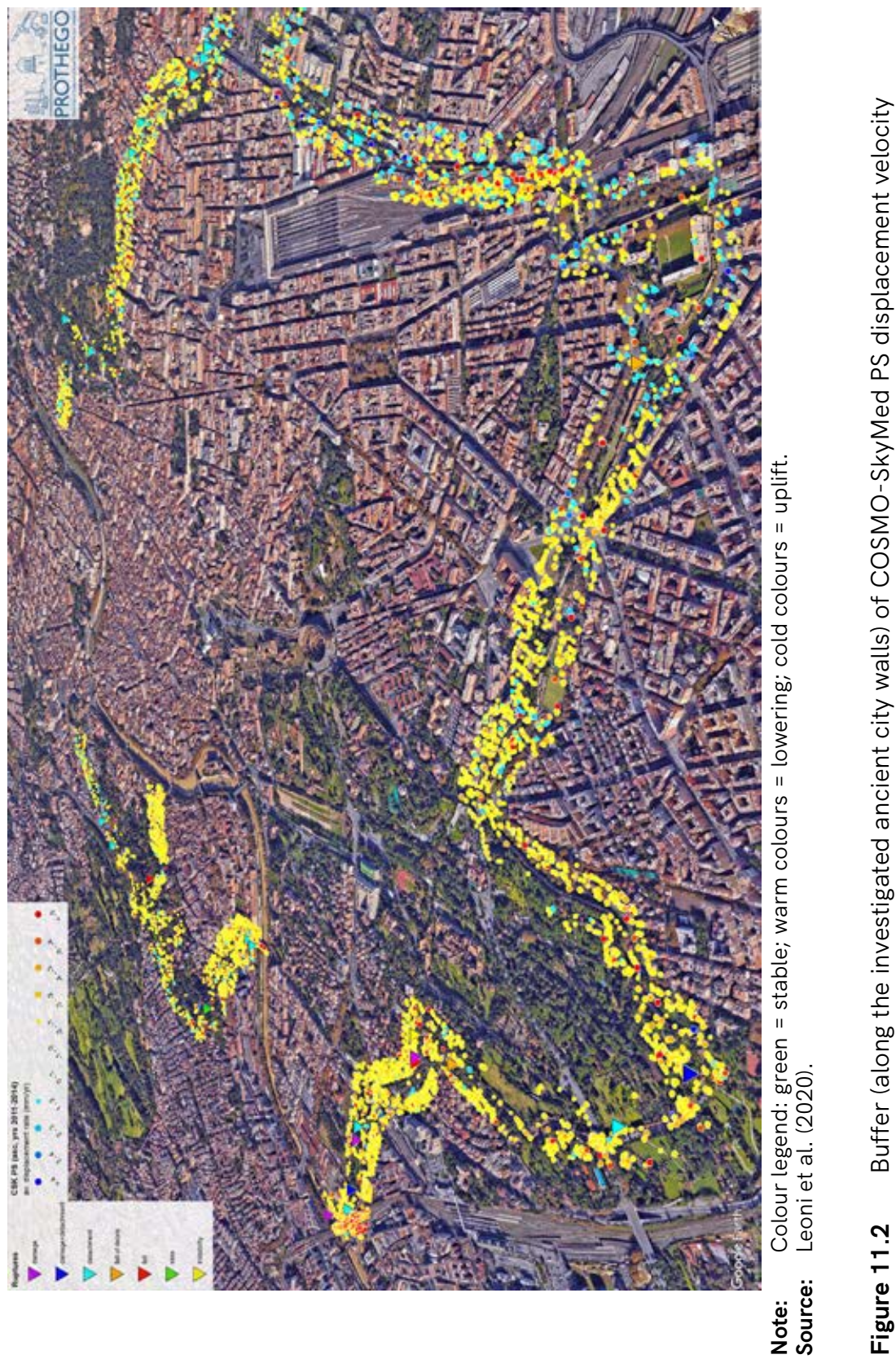


cooperation with the Derwent Valley Mills World Heritage team (Harrison et al. 2018).

\section{The Alhambra and Albaycin district (Spain)}

All the Alhambra and Albaycin UNESCO monumental complex in Granada was investigated (both regional and local scale) with satellite data (Sentinel-1 and CSKmed ${ }^{\circ}$ ). It was not possible to highlight any deformation trends from satellite analysis, even though this was of extreme detail. The landslide that threatens a portion of the north cliff (known as the 'Tacco de San Pedro') was analysed with the support of new technologies (e.g. Terrestrial Laser Scanner (TLS), Unmanned Aerial Vehicle (UAV), digital photogrammetry). An advanced 3D stability model was implemented to support the site manager for future mitigation measures and monitoring polices. The CSKmed ${ }^{\circ}$ high-resolution radar images were used instead, with great success, for the control of an Arab palace (Dar Al Horra Palace) in the Albaycin neighbourhood, affected since 2014 by a potential slow landslide. This case study was implemented in cooperation with the Patronato de la Alhambra y Generalife.

\section{The Choirokoitia archaeological site (Cyprus)}

The Neolithic settlement of Choirokoitia, occupied from the seventh to the fourth millennium $\mathrm{BC}$, is one of the most important prehistoric sites in the eastern Mediterranean, and has been included in the UNESCO World Cultural Heritage list since 1988. The site was recently threatened by rockfall, erosion and subsidence. The local-scale monitoring methodology included in situ observation; remote sensing techniques, such as PS techniques, were used to validate the impact of geo-hazards. Topographic surveying using differential Global Navigation Satellite System (GNSS), UAV images, photogrammetry and InSAR data was used to map slow ground movements, which were then compared and validated with ground-based geotechnical monitoring in order to evaluate the cultural heritage site's deformation trend and to understand its behaviour over time (Themistocleus and Danzi 2020).

\section{The Tramuntana Range Cultural Landscape (Spain)}

The Bàlitx area is located on the steep coastal side of the Tramuntana Range (Majorca); a mountainous region which was declared a World Heritage Site by UNESCO in 2011 in the cultural landscape category. The Bàlitx site was occupied by farming areas with dry-stone constructions and water-storing systems of both Roman and Islamic origin. Block spreading morphologies were identified along the escarpment. Additionally, numerous geomorpholog- 
ical slope features were identified in the area: landslides, rockfalls and, more specifically, long and deep cracks in the hanging wall block of the fault, which also revealed active lateral spreading processes. Satellite SAR images from the ALOS PALSAR mission were exploited; these covered a period spanning from 2007 to 2010. The images were processed using the Persistent Scattered Interferometry (PSI) technique. The PSInSAR results revealed that the rate of movement for the Bàlitx lateral spreading is extremely low $(-5.2 \mathrm{~mm} /$ year on average), but major activity was detected in the northeast sector, where velocity rates can reach values of up to $-16 \mathrm{~mm} /$ year. The Bàlitx case study could provide a testimony to the effects of mass movements and coastal dynamics in an exceptional example of a Mediterranean agricultural landscape (Mateos et al. 2018).

\section{Conclusion}

The major outcome of the PROTHEGO project is the application of the new space technology, based on radar interferometry - which is now capable of monitoring surface deformation with millimetre precision - to the cultural heritage sector. By applying this methodology to 399 UNESCO World Heritage Sites in Europe and by integrating these data with existing databases of geo-hazards, PROTHEGO identified and ranked the most critical cultural heritage sites over the entirety of Europe. PROTHEGO's goals are also to enhance cultural heritage management practices at the national level; reinforce institutional support and governance through knowledge and innovation; identify, assess and monitor risks; and strengthen disaster preparedness for heritage properties in the future. The project promoted interdisciplinary and collaborative R\&D activities, transferring the highest level of knowledge, quality and standards from space and earth sciences to cultural heritage conservation sciences. A general agreement around the use of satellite services for monitoring of geo-hazards affecting cultural heritage needs to be implemented in order to define best-practice guidelines and standard methodologies for adoption by practitioners in this field. A multidisciplinary approach between earth science disciplines, data providers and data processers, and from within the cultural heritage protection domain, is required to truly make a positive difference. There is a need to develop simple and dedicated tools or downstream services which enable practitioners to make better use of available data and knowledge about geo-hazards and how these hazards may affect cultural heritage. Cultural heritage is an important pillar both for economic and social impacts across Europe. Better understanding of natural hazard processes 
affecting cultural heritage through low-impact monitoring techniques like satellite methodologies improves resilience and reduces general vulnerability, saving money from post-disaster recovery and obtaining long-term cost benefits.

The PROTHEGO project has certainly reduced the distance between the world of cultural heritage conservation and the earth sciences and space domains. Finally, the following major outcomes and future perspectives can be mentioned from the project:

1. incorporation of InSAR methodology into the management plans of UNESCO sites, as discussed in the final meeting at UNESCO headquarters in Paris;

2. emphasizing the relevance of proper management at both international and national level;

3. enhancement of cultural heritage risk awareness and risk management, through an interdisciplinary approach;

4. strengthening disaster risk assessment and management at the local level (UNESCO, 2010);

5. a new potential market in the field of low-impact monitoring techniques;

6. involvement and awareness of final users and stakeholders (e.g. site managers, tourists, citizens) for long-term sustainable mitigation measures;

7. emphasizing the relevance of low-impact techniques in diagnosing and monitoring heritage sites;

8. emphasizing the relevance of low-impact techniques, sustainable practices and involvement of local knowledge and materials to preserve existing sites;

9. application of the PROTHEGO strategy to other countries, as discussed during the project meeting in Petra, Jordan;

10. enlargement of number and type of hazards to assess, such as flood, fire, man-made disasters and others.

In conclusion, it is advisable that the PROTHEGO approach is enlarged and implemented in all the European cultural heritage sites (not only to UNESCO WHL) in order to easily produce tools and downstream services. A specific summer school is currently under organization to promote the approach in the UNESCO sites outside Europe. 


\section{References}

Cigna, F. and D. Tapete (2017), 'PROTHEGO Deliverable D.02.01: Available satellite InSAR data for the European WHL sites, Version 1.0. JPI-CH Heritage Plus PROTHEGO project', Open Report. Date DD/03/2017, iii, 18, 23, accessed 8 May 2021 at http://www.prothego.eu/downloads.html

Harrison, A.M., A. Novellino, P.R.N Hobbs et al. (2018), 'Local scale investigation and advanced modelling of the geo-hazards affecting the Derwent Valley Mills World Heritage Case Study Site', Version 1.0. Nottingham, UK: British Geological Survey, 51. (OR/18/008).

Leoni G., Spizzichino D., Marcelli M. and C. Carta (2020), 'Il monitoraggio satellitare nelle aree archeologiche: il caso delle mura Aureliane di Roma', in A. Russo and I. Della Giovampaola (eds), Monitoraggio e Manutenzione delle Aree Archeologiche: Cambiamenti Climatici, Dissesto Idrogeologico, Degrado Chimico-Ambientale. Atti del Convegno Internazionale di Studi, Roma, Curia Iulia, 20-21 March 2019. Collana Bibliotheca Archaeologica. L'Erma di Bretschneider, 217.

Margottini, C. and S. Menoni (2018), 'Hazard assessment', in P. Bobrowsky and B. Marker (eds), Encyclopedia of Engineering Geology. Encyclopedia of Earth Sciences Series. Cham: Springer.

Mateos, R.M., P. Ezquerro, J.M. Azañón et al. (2018), 'Coastal lateral spreading in the world heritage site of the Tramuntana Range (Majorca, Spain). The use of PSInSAR monitoring to identify vulnerability', Landslides, doi 10.1007/s10346-018-0949-5, received: 1 December 2017, accepted: 12 January 2018, (c) Springer-Verlag GmbH Germany, part of Springer Nature.

Michalski, S. and J.L. Pedersoli, Jr. (2017), The ABC Method: A Risk Management Approach to the Preservation Of Cultural Heritage. Canadian Conservation Institute.

Pavlova, I., A. Makarigakis, T. Depret and V. Jomelli (2017), 'Global overview of the geological hazard exposure and disaster risk awareness at world heritage sites', Journal of Cultural Heritage, 28, 151-7.

Spizzichino, D., G. Leoni, V. Comerci et al. (2016), 'PROTHEGO deliverable D.01.01: UNESCO cultural heritage vs. natural hazards at European scale', Version 1.0. JPICH Heritage Plus PROTHEGO project, Open Report, Date 15 December 2016, accessed 8 May 2021 at http://www.prothego.eu/downloads.html

Taboroff, J. (2000), 'Cultural heritage and natural disasters: incentives for risk management and mitigation. Managing disaster risk in emerging economies', New York: World Bank, Disaster Management Risk, 2, 71-9.

Themistocleous, K., A. Agapiou, B. Cuca et al. (2016a), 'Methodology for locale-scale monitoring for the PROTHEGO project: the Choirokoitia case study', Proceedings SPIE 2016 conference.

Themistocleous, K., B. Cuca, A. Agapiou et al. (2016b), 'The protection of cultural heritage sites from geo-hazards: the PROTHEGO project', Digital Heritage. Progress in Cultural Heritage: Documentation, Preservation, and Protection, 6th International Conference, EuroMed 2016, Nicosia, Cyprus, 31 October-5 November 2016, Proceedings, Part II, Springer Verlag.

Themistocleous, K. and C. Danezis (2020), 'Monitoring cultural heritage sites affected by geo-hazards using in situ and SAR data: the Choirokoitia case study', in D. Hadjimitsis et al. (eds), Remote Sensing for Archaeology and Cultural Landscapes. Springer Remote Sensing/Photogrammetry. Cham: Springer at https://doi.org/10 .1007/978-3-030-10979-0_16 
UNESCO, ICCROM, ICOMOS and IUCN (2010), Managing Disaster Risks for World Heritage. World Heritage Resource Manual, Paris: UNESCO, 1-6.

Valagussa, A., P. Frattini, G.B. Crosta and N. Berta (2018), 'Definition of GIS-based multi-criteria methodology for the selection of case studies', Version 1.0. JPICH Heritage Plus PROTHEGO project, Open Report, Date 1 February 2018, accessed 8 May 2021 at http://www.prothego.eu/

Valagussa, A., P. Frattini, G.B. Crosta et al. (2021), 'Multi-risk analysis on European cultural and natural UNESCO heritage sites', Natural Hazards, 105, 2659-76 at https://doi.org/10.1007/10.1007/s11069-020-04417-7 
Daniele Spizzichino and Claudio Margottini - 9781788974639 Downloaded from PubFactory at 04/26/2023 07:32:30AM 